\title{
Healthy Lifestyle Behavior among the Female Employees of University of Hail, Ksa
}

\author{
Jerlyn A. Enrera, Marivic R. Jamison, Amani Lafe Abdullah Enazy, Meshael \\ Usweed Al-Humaid \\ 1 (Department of Clinical Laboratory Science, College of Applied Medical Sciences, University of Hail, \\ Kingdom of Saudi Arabia) \\ 2 (Department of Clinical Nutrition, College of Applied Medical Sciences, University of Hail, Kingdom of Saudi \\ Arabia) \\ 3 (Students, Department of Clinical Nutrition, College of Applied Medical Sciences, University of Hail, Kingdom \\ of Saudi Arabia)
}

\begin{abstract}
This research was intended to determine the healthy lifestyle behavior of the female employees of University of Hail, KSA. It sought to answer to following questions; (1) What is the demographic profile of the respondents in terms of age, marital status, nationality, occupation, monthly income and length of service in the university. (2) What is the healthy lifestyle behavior of the respondents in terms of nutrition, physical activity, managing stress and healthy habits? A Researcher-made questionnaire was used to gather the data and the statistical tools were frequency and percentage and mean. Most of the respondents were twenty six to thirty five years old, married, Philippines, academic staff, two years length of service, income of five thousand to ten thousand Saudi riyals. The healthy lifestyle behavior of the respondents revealed that they often practice healthy habits and are often able to manage stress. The respondents sometimes adhere to proper nutrition and sometimes engage in physical activity. Further statistical treatment shows that the respondents sometimes adhere to the proper healthy lifestyle behavior.
\end{abstract}

Key Words: Female employee, Healthy habits, Healthy lifestyle, Managing stress, Nutrition, Physical activity

\section{Background of the Study}

\section{INTRODUCTION}

Everybody experience a bad day at work. No matter how focused you are at work, nothing to be going right sometimes. When you are not feeling well, and you tend to lose your perspective.

Globally, non-communicable diseases are the leading causes of death, killing more people each year than all other causes of death. According to WHO Report 2002, [1] the most important risks of non-communicable disease included high blood pressure, high concentrations of cholesterol in the blood, inadequate intake of fruit and vegetables, being overweight or obese, physical inactivity and unhealthy habits. Five of these risk factors are closely related to diet and physical activity, and dietary patterns that have a role in the development of cardiovascular disease, obesity, and diabetes mellitus.

According to Centers for Disease Control and Prevention, 2009, [2] any person suffers non communicable chronic disease which begins by changing everyday behaviors that relate to eating, health habits, stress and physical activity. That means people may need to change their knowledge, attitudes, and beliefs. Individual's health behaviors are strongly influenced and their choices are largely determined by the groups and organizations that surround them and the community and society they live in.

In Saudi Arabia, obesity and a sedentary lifestyle are two characteristics seen as normal, because of their high prevalence, even though both can be prevented. In a study of obesity in the Eastern Province of Saudi Arabia Dr. Rasheed, [3] states that obesity among females, especially above the age of 40, has reached epidemic proportions. In this age group $78.4 \%$ were over-nourished and in younger groups up to $30-40 \%$ were overweight or obese (Overweight, 1996). With these numbers being so high, obesity related diseases such as Diabetes are surprisingly high.

Based on the research studies conducted by NIOSH (1998) [4] shows that unhealthy lifestyle behavior conditions are actually associated with increased absenteeism, tardiness and intention by the workers to quit their job and even death occurs. It damages one's productivity because unhealthy lifestyle behavior on nutrition, physical activity, stress and health habits can slow down the process of the body and mind, makes incompetent, ineffective, and inefficient employee. (Randoff, 1996) [5]

Many employers recognize that they have an obligation to the health and wellbeing of their employees. Investing in the health of the employees can also bring business benefits such as reduced sickness absence, increased loyalty and better staff retention. (National Institute for Health and Clinical Excellence, 2008). [6] 
Due to these prevailing issues, the researchers were motivated to conduct the study to predict which of those significant variables affects the lifestyle behavior of the female employees of the university.

Moreover, this study may provide an insight that will give the administrators a wider frame of reference in establishing an avenue for the female employees to have healthy lifestyle behavior and to design appropriate interventions to improve.

\section{Statement of the problem:}

This study specifically sought to answer the following questions:

1. What is the demographic profile of the respondents in terms of age, marital Status, nationality, occupation, occupation, monthly income and length of service in the university

2. What is the healthy lifestyle behavior of the respondents in terms of nutrition, physical activity, managing stress and healthy habits?

\section{Objectives}

The general purpose of this research was to determine the healthy lifestyle behavior of the female employee of the University of Hail.

This study will be significant to the following:

Female Employee. This study is significant to female employees to have greater prospect of long life, avoiding lifestyle diseases.

Human Resource. The study serves as a guide in hiring and renewing contract of the academic employee to be potential, productive and competent employee.

School Clinic. Counseling an employee member affected by unhealthy lifestyle behavior.

\section{Methodology}

The method includes research design, sampling design, statistical treatment, instrument and procedure of the study.

Female academic and administrative employees were surveyed. The design used was descriptive research, sampling design was quota sampling technique and statistical tools used were frequency and percentage and mean.

\section{Instruments}

The proponents used researcher-made questionnaire for gathering data on the healthy lifestyle behavior which includes the demographic profile of the employees, the lifestyle behavior which includes nutrition, physical activity, managing stress and healthy habits.

The questionnaire consists of two parts. Part one aim to gather information on the demographic profile of the employee such as age, nationality, occupation, monthly income, marital status, length of service in the university. Part two used gathered data regarding the survey questionnaire to identify healthy lifestyle behavior among the employee.

It will be evaluated using the criteria below.

5 Always (means that you do it for the entire seven (7) days in a week)

4 Often (means that you do it from five (5) to six (6) days in a week)

3 Sometimes (means that you do it from three (3) to four (4) days in a week)

2 Rarely (means that you do it from one (1) to two (2) days in a week)

1 Never (means that you are NOT doing it) 


\section{Figures, Tables And Results}

Figure 1.A

Age Distribution of the Respondents

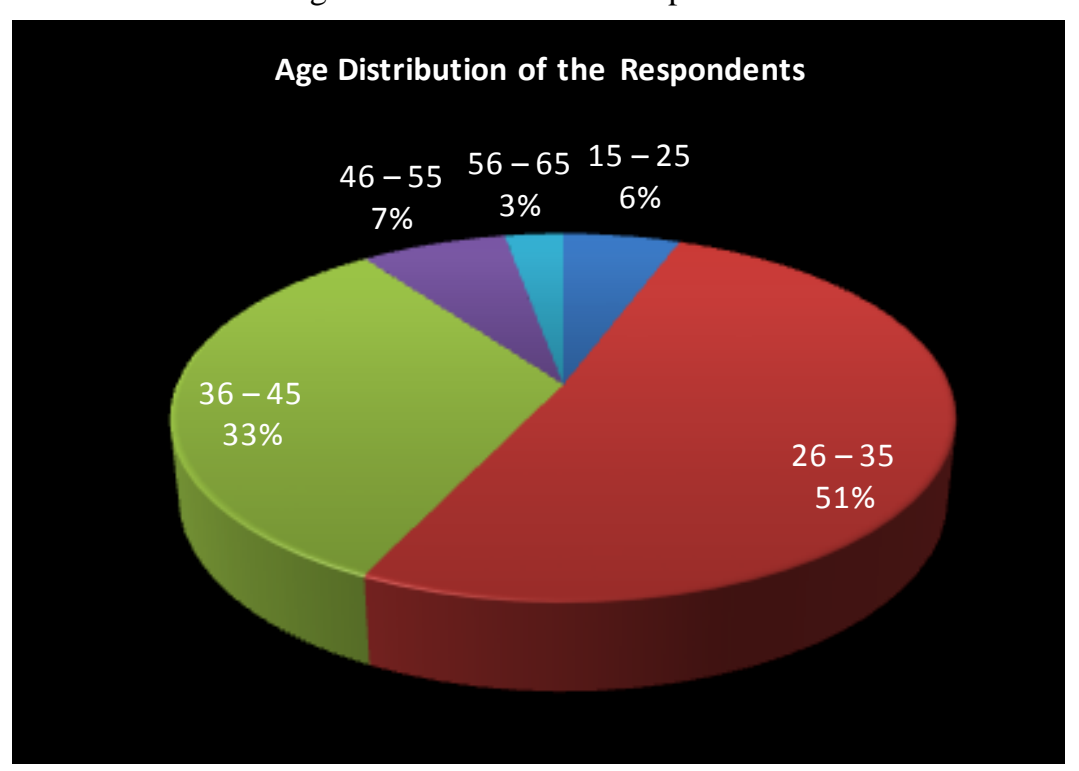

Fig. 1.A shows the age distribution of the respondents. This tells us that fifty one point four percent $(51.4 \%)$ belonged to the age group twenty six to thirty five $(26-35)$ years old, followed by thirty two point nine percent $(32.9 \%)$ belonged to age group thirty six to forty five $(36-45)$ years old, seven point one percent $(7.1 \%)$ belonged to age group forty six to fifty five $(46-55)$ years old, five point seven percent $(5.7 \%)$ belonged to age group fifteen to twenty five (15-25) years old and two point nine percent $(2.9 \%)$ belonged to age group fifty six to sixty five $(56-65)$ years old.

This means that most of the respondents belonged to the age group twenty six to thirty five (26-35) years old and the least are from the age group fifty six to sixty five $(56-65)$ years old.

Figure 1.B

Marital Status Distribution of the Respondents

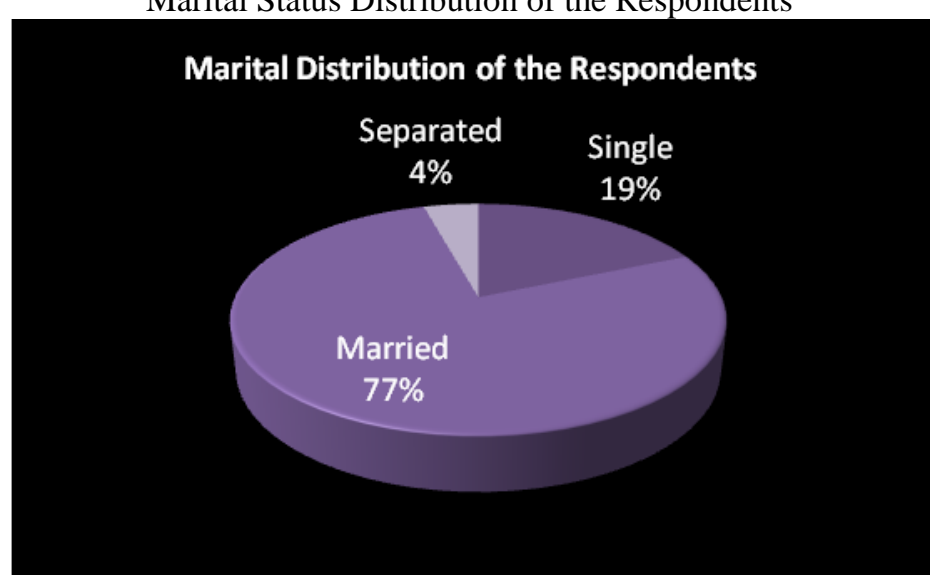

Fig. 1.B shows the marital status distribution of the respondents. This tells us that seventy seven point one percent $(77.1 \%)$ were married, followed by eighteen point six percent $(18.6 \%)$ were single and four point three percent $(4.3 \%)$ were separated.

This means that most of the respondents were married and the least were separated.

$$
\text { Figure 1.C }
$$

Nationality Distribution of the Respondents 


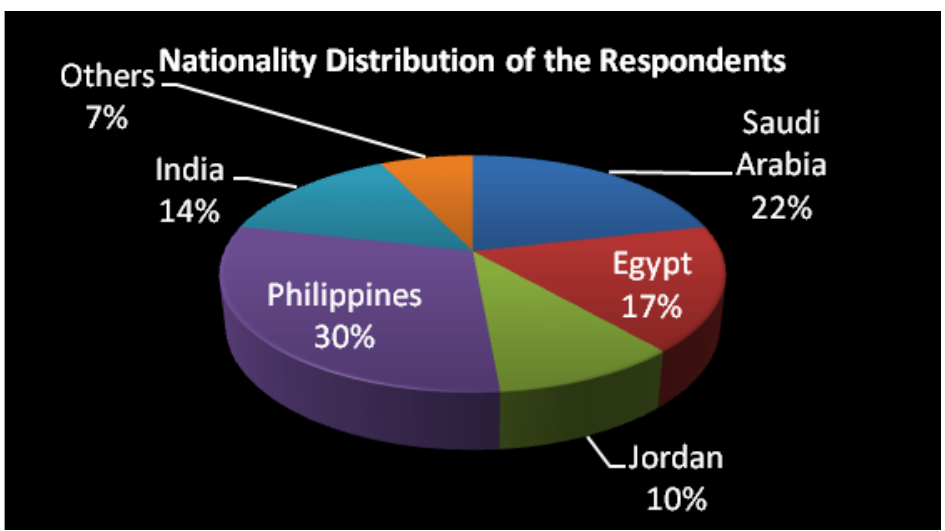

Fig. 1.C shows the nationality distribution of the respondents. This tells us that thirty percent (30\%) were from the Philippines, followed by twenty one point four percent $(21.4 \%)$ were from Saudi Arabia, seventeen point one percent $(17.1 \%)$ were from Egypt, fourteen point three percent $(14.3 \%)$ were from India, ten percent $(10 \%)$ were from Jordan, and seven point one percent $(7.1 \%)$ were classified as other nationalities.

This means that most of the respondents came from the Philippines and the least came from other nationalities.

Figure 1.D

Occupation Distribution of the Respondents

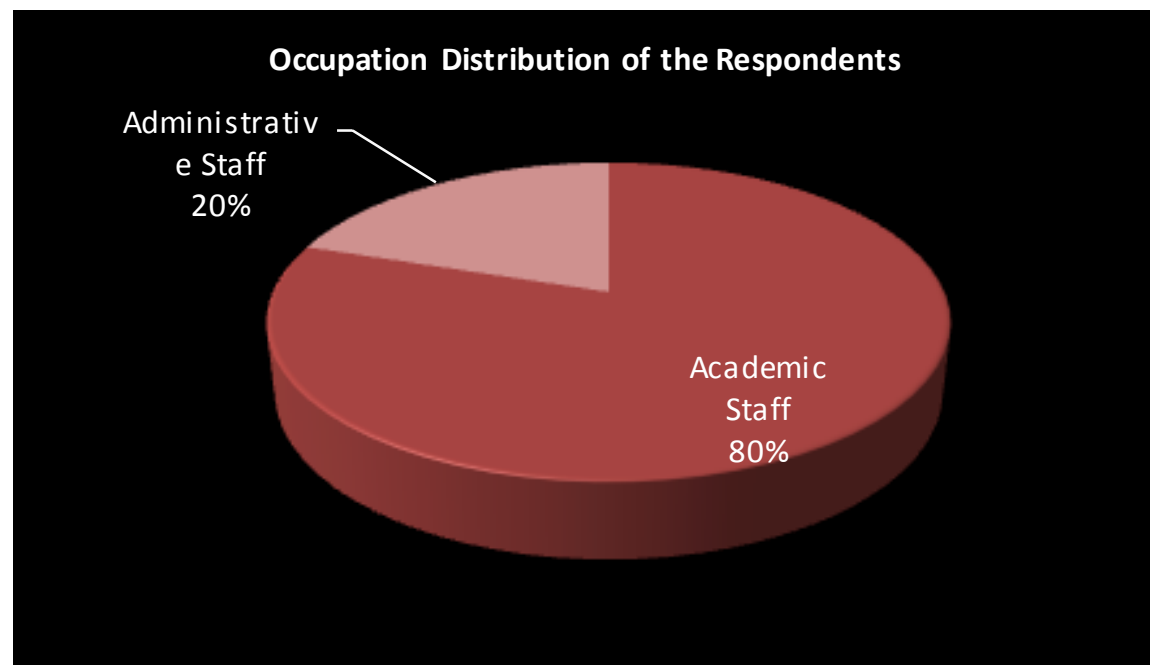

Fig. 1.D shows the occupation distribution of the respondents. The table tells us that eighty percent $(80 \%)$ were academic staff, whereas, twenty percent $(20 \%)$ were administrative staff.

This means that most of the respondents were academic staff such as lecturers and professors.

Figure 1.E

Length of Service Distribution of the Respondents

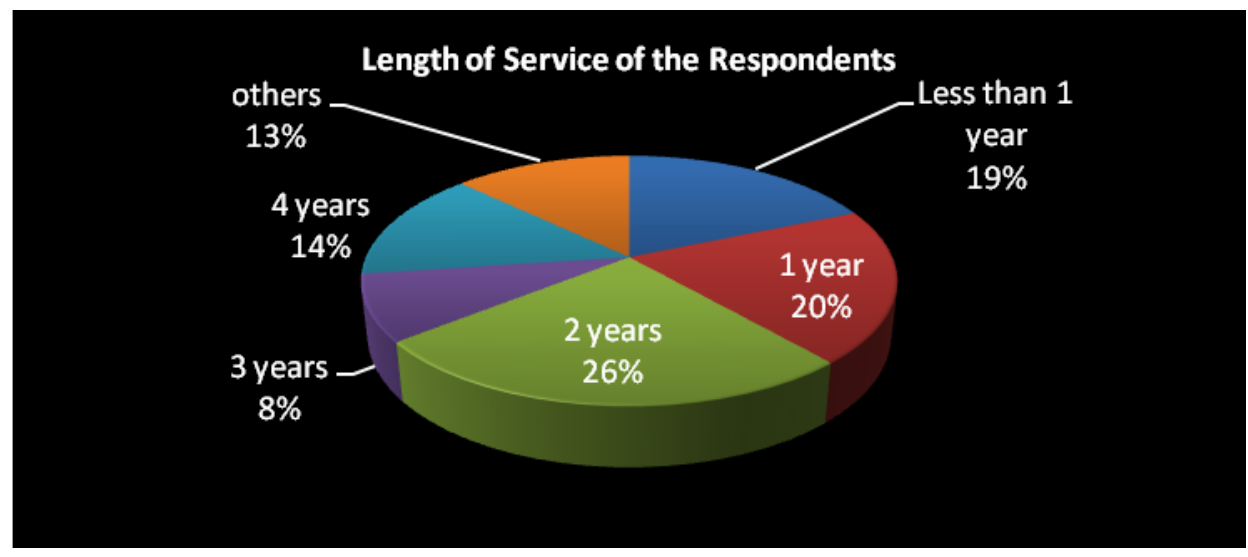


Fig. 1.E presents the length of service distribution of the respondents. Twenty five point seven percent $(25.7$ $\%$ ) of the respondents had two (2) years of length of service, followed by twenty percent (20\%) had one (1) year, eighteen point six $(18.6 \%)$ had less than one (1) year, fourteen point three percent $(14.3 \%)$ had four (4) years, twelve point nine percent $(12.9 \%)$ had others or more than five years and eight point six $(8.6 \%)$ had three (3) years length of service. This means that most of the respondents had two (2) years length of service and the least had three (3) years.

Figure 1.F

Income Distribution of the Respondents

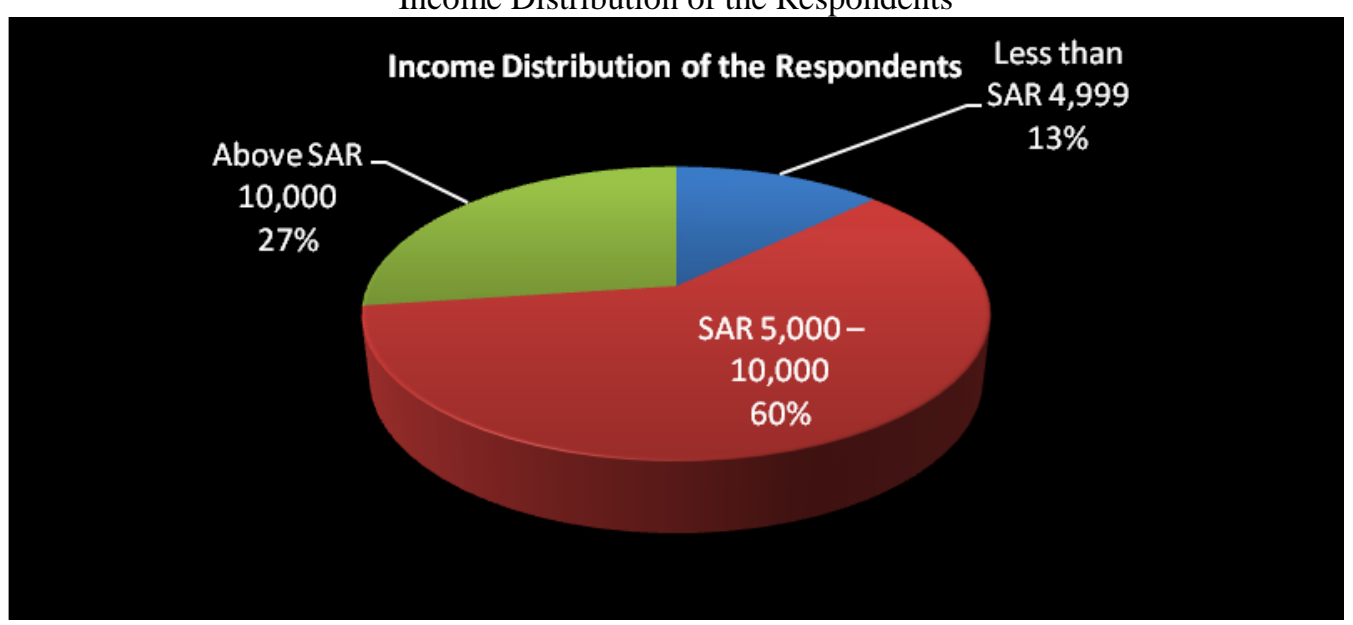

Figure 1.F presents the income distribution of the respondents. The table tells us that sixty percent $(60 \%)$ received an income ranging from five thousand to ten thousand Saudi Riyals (SAR 5,000 - 10,000), followed by twenty seven point one percent $(27.1 \%)$ received an income above ten thousand Saudi Riyals (SAR 10,000) and twelve point nine percent $(12.9 \%)$ received an income less than four thousand nine hundred ninety nine (SAR 4,999). This means that most of the respondents received an income ranging from five thousand to ten thousand Saudi Riyals (SAR 5,000 - 10,000) received an income less than four thousand nine hundred ninety nine (SAR 4,999).

TABLE 1.A

Mean Result on Respondent's Healthy Lifestyle Behavior on Nutrition

\begin{tabular}{|c|c|c|c|}
\hline & Statement & Mean & Interpretation \\
\hline 1 & $\begin{array}{l}\text { Eat regular meals during the day, as breakfast, lunch and } \\
\text { supper. }\end{array}$ & 3.84 & Often \\
\hline 2 & Drink eight (8) to ten (10) glasses of water daily. & 3.30 & Sometimes \\
\hline 3 & $\begin{array}{l}\text { Select appropriate servings from the food guide pyramid } \\
\text { each day. }\end{array}$ & 2.89 & Sometimes \\
\hline 4 & Restrict the amount of fat and salt in my diet. & 3.34 & Sometimes \\
\hline 5 & Consume as many calories as required each day. & 3.17 & Sometimes \\
\hline 6 & Take multi vitamins or other food supplements. & 2.57 & Sometimes \\
\hline 7 & $\begin{array}{l}\text { Eat a balanced breakfast before I come to work. (whole } \\
\text { grain and healthy fiber, some lean protein, and maybe } \\
\text { even some fruits and veggies for the day) }\end{array}$ & 2.87 & Sometimes \\
\hline 8 & $\begin{array}{l}\text { Consume sugary drinks, fruit juices more than one (1) } \\
\text { cup daily. }\end{array}$ & 3.46 & Sometimes \\
\hline 9 & $\begin{array}{l}\text { Prefer to drink tea than coffee whenever there is a need } \\
\text { for a warm drink. }\end{array}$ & 2.97 & Sometimes \\
\hline \multirow[t]{2}{*}{10} & $\begin{array}{l}\text { Add a lot of syrup, whole milk or whipped cream when } \\
\text { drinking coffee. }\end{array}$ & 3.9 & Often \\
\hline & Grand Mean & 3.23 & Sometimes \\
\hline
\end{tabular}

Table 1.A presents the results of the healthy lifestyle behavior of the respondents on nutrition. This tells us that most of the respondents often add a lot of syrup, whole milk or whipped cream when drinking coffee (3.90) and eat regular meals during the day, as breakfast, lunch and supper (3.84). On the other hand, the respondents sometimes consume sugary drinks, fruit juices more than one cup daily (3.46), restrict the amount of fat and salt in their diet (3.34), drink eight (8) to ten (10) glasses of water daily (3.30), consume as many calories as required each day (3.17), prefer to drink tea than coffee whenever there is a need for a warm drink (2.97), select appropriate servings from the food guide pyramid each day (2.89), eat a balanced breakfast before coming to 
work. (Whole grain and healthy fiber, some lean protein, and maybe even some fruits and veggies for the day) (2.87) and take multi vitamins or other food supplements (2.57).

This means that most of the respondents add a lot of syrup, whole milk or whipped cream when drinking coffee and the least take multi vitamins or other food supplements. This implies that respondents do not just drink plain coffee but add syrup, creamer or milk to it. The respondents also just rely on the vegetables or meat as sources of vitamins.

TABLE 1.B

Mean Result on Respondent's Healthy Lifestyle Behavior on Physical Activity

\begin{tabular}{|c|l|c|c|}
\hline & \multicolumn{1}{|c|}{ Statement } & Mean & Interpretation \\
\hline 1 & Do at least thirty (30) minutes of aerobic exercise. & 2.24 & Rarely \\
\hline 2 & $\begin{array}{l}\text { Use the stairs instead of the lift or elevators or } \\
\text { escalators. }\end{array}$ & 4.34 & Often \\
\hline 3 & $\begin{array}{l}\text { Run errands or go to speak to someone in another } \\
\text { part of the building or on campus rather than } \\
\text { sending e-mail. }\end{array}$ & 3.27 & Sometimes \\
\hline 4 & $\begin{array}{l}\text { Do vigorous activity that elevates the heart rate for } \\
\text { twenty (20) minutes. }\end{array}$ & 2.30 & Rarely \\
\hline 5 & Do walking for pleasure ( in malls, parks, outdoors). & 3.24 & Sometimes \\
\hline 6 & $\begin{array}{l}\text { Take a walk on a break or use a part of the lunch } \\
\text { hour. }\end{array}$ & 2.70 & Sometimes \\
\hline 7 & Do floor exercise bending, stretching, yoga) & 2.07 & Rarely \\
\hline 8 & Preparing food, cooking and washing dishes. & 4.69 & Always \\
\hline 9 & $\begin{array}{l}\text { Cleaning the house, doing laundry and ironing } \\
\text { clothes. }\end{array}$ & 4.51 & Always \\
\hline 10 & $\begin{array}{l}\text { Do stretching break every two(2) - three (3) hours } \\
\text { (e.g. raising arms overhead). }\end{array}$ & 2.90 & Sometimes \\
\hline & $\quad$ Grand Mean & 3.23 & Sometimes \\
\hline
\end{tabular}

Table 1.B presents the results of the healthy lifestyle behavior of the respondents on physical activity. This tells us that most of the respondents prepare food, cooking and washing dishes (4.69) and clean the house, doing laundry and ironing clothes (4.51). The respondents often use the stairs instead of the lift or elevators or escalators (4.34). Sometimes the respondents run errands or go to speak to someone in another part of the building or on campus rather than sending e-mail (3.27), do walking for pleasure ( in malls, parks, outdoors) (3.24), do stretching break every two(2) - three (3) hours (e.g. raising arms overhead) (2.90) and take a walk on a break or use a part of the lunch hour (2.70). However, the respondents rarely do vigorous activity that elevates the heart rate for twenty (20) minutes (2.30), do at least thirty (30) minutes of aerobic exercise (2.24) and do floor exercise (bending, stretching, yoga) (2.07).

This means that most of the physical activity of the respondents is on preparing food, cooking and washing dishes and the least do floor exercise such as bending, stretching and yoga. This implies that the physical activity of the respondents revolves in doing household chores. However, the respondents do not usually engage in other physical exercises that will tend to increase cardiac output and lung capacity.

TABLE 1.C

Mean Result on Respondent's Healthy Lifestyle Behavior on Managing Stress

\begin{tabular}{|c|c|c|c|}
\hline & Statement & Mean & Interpretation \\
\hline 1 & I am able to identify situations in daily life that cause stress. & 4.11 & Often \\
\hline 2 & I regularly perform exercises designed to relieve tension. & 2.61 & Sometimes \\
\hline 3 & $\begin{array}{l}\text { I take time out during the day to relax by listening to music or } \\
\text { watching a comedy show. }\end{array}$ & 3.33 & Sometimes \\
\hline 4 & I enjoy my job as it develops my skills and interests. & 4.07 & Often \\
\hline 5 & I live within my means without getting into debt. & 3.91 & Often \\
\hline 6 & $\begin{array}{l}\text { If someone is bothering me, I voice out my feelings in an open and } \\
\text { respectful way. }\end{array}$ & 3.66 & Often \\
\hline 7 & $\begin{array}{l}\text { I analyze my daily tasks and distinguish between "should" and } \\
\text { "musts" and drop the tasks that aren't truly necessary to the bottom } \\
\text { of the list. }\end{array}$ & 4.04 & Often \\
\hline 8 & I repeatedly argue about the same topic with the same people. & 3.71 & Often \\
\hline 9 & I usually control the clutter in my work area. & 3.79 & Often \\
\hline \multirow[t]{2}{*}{10} & $\begin{array}{l}\text { Take a moment to reflect on all the things that I appreciate in my } \\
\text { life. }\end{array}$ & 4.10 & Often \\
\hline & Grand Mean & 3.73 & Often \\
\hline
\end{tabular}


Table 1.C presents the results of the healthy lifestyle behavior of the respondents on managing stress. This tells us that most of the respondents often are able to identify situations in daily life that cause stress (4.11), take a moment to reflect on all the things that they appreciate in their life (4.10), enjoy the job as it develops the skills and interests (4.07), analyze the daily tasks and distinguish between "should" and "musts" and drop the tasks that aren't truly necessary to the bottom of the list (4.04), live within their means without getting into debt (3.91), usually control the clutter in the work area (3.79), repeatedly argue about the same topic with the same people (3.71) and voice out their feelings in an open and respectful way (3.66). However, the respondents sometimes take time out during the day to relax by listening to music or watching a comedy show (3.33) and perform exercises designed to relieve tension (2.61).

This means that in terms of managing stress, most of the respondents are able to identify situations in daily life that causes stress and the least is on performing regular exercises designed to relieve tension. This implies that the respondents are aware of the possible stressors both in work and at home. However, the respondents may not have enough knowledge on the different exercises to relieve tension that can be done in the office.

TABLE 1.D

Mean Result on Respondent's Healthy Lifestyle Behavior on Healthy Habits

\begin{tabular}{|c|c|c|c|}
\hline & Statement & Mean & Interpretation \\
\hline 1 & Brush my teeth at least two (2) times a day. & 4.47 & Always \\
\hline 2 & $\begin{array}{l}\text { Get an adequate amount of sleep at an average of eight (8) hours } \\
\text { each night. }\end{array}$ & 3.36 & Sometimes \\
\hline 3 & $\begin{array}{l}\text { Do regular self-examination and seek medical advice when } \\
\text { symptoms are present. }\end{array}$ & 3.09 & Sometimes \\
\hline 4 & Do regular medical check-up and submit for laboratory tests. & 2.39 & Rarely \\
\hline 5 & Monitor body weight. & 3.69 & Often \\
\hline 6 & $\begin{array}{l}\text { Abstain or limit sexual activity to one partner and practice safe } \\
\text { sex. }\end{array}$ & 3.47 & Sometimes \\
\hline 7 & $\begin{array}{l}\text { Read product labels and investigate their effectiveness before I } \\
\text { buy them. }\end{array}$ & 4.43 & Often \\
\hline 8 & $\begin{array}{l}\text { Avoid using products that have not been proven by research to } \\
\text { be effective. }\end{array}$ & 3.72 & Often \\
\hline 9 & Take a bath or a shower bath. & 4.76 & Always \\
\hline \multirow[t]{2}{*}{10} & I smoke cigarette at least 1 or more sticks a day. & 4.89 & Always \\
\hline & Grand Mean & 3.83 & Often \\
\hline
\end{tabular}

Table 1.D presents the results of the healthy lifestyle behavior of the respondents on healthy habits. This tells us that most of the respondents always smoke cigarette at least 1 or more sticks a day (4.89), take a bath or a shower bath (4.76) and brush my teeth at least two (2) times a day (4.47). The respondents often read product labels and investigate their effectiveness before buying them (4.43), avoid using products that have not been proven by research to be effective (3.72) and monitor body weight (3.69). The respondents sometimes abstain or limit sexual activity to one partner and practice safe sex (3.47), get an adequate amount of sleep at an average of eight (8) hours each night (3.36) and do regular self-examination and seek medical advice when symptoms are present (3.09). However, the respondents rarely do regular medical check-up and submit for laboratory tests (2.39).

This means that most of the respondent healthy habits involved smoking cigarette at least 1 or more sticks a day and the least do regular medical check-up and submit for laboratory tests. This implies that the respondents are not well informed on the health risk of cigarette smoking and the advantages of having regular medical check-up.

TABLE 1.E

Mean Result on Healthy Lifestyle Behavior

\begin{tabular}{|l|c|c|}
\hline \multicolumn{1}{|c|}{ Healthy Lifestyle Behavior } & Mean & Interpretation \\
\hline Nutrition & 3.23 & Sometimes \\
\hline Physical Activity & 3.23 & Sometimes \\
\hline Managing Stress & 3.73 & Often \\
\hline Healthy Habits & 3.83 & Often \\
\hline Grand Mean & 3.50 & Sometimes \\
\hline
\end{tabular}

Table 1.E presents the results of the healthy lifestyle behavior of the respondents on healthy habits. This tells us that most of the respondents often practice healthy habits (3.83), followed by managing stress (3.73), nutrition and physical activity (3.23). Further statistical treatment shows that the respondents sometimes follow the proper healthy lifestyle behavior (3.50). 


\section{Discussion}

Most of the respondents practice healthy habits and the least on proper nutrition and engaging on physical activity. This tells us that most of the respondents often add a lot of syrup, whole milk or whipped cream when drinking coffee and eat regular meals during the day, as breakfast, lunch and supper. This implies that respondents do not just drink plain coffee but add syrup, creamer or milk to it to add more calories.

According to the research study of Dr. Jonathan Purnell at Oregon Health Science University [7] his study revealed that the adults who got at least 25 percent of their calories from added sugar were almost three times more likely to die of heart problems than those who consumed the least - less than 10 percent. For those who got more than 15 percent - or the equivalent of about two cans of sugary soda out of 2,000 calories daily - the risk was almost 20 percent higher than the safest level. Sugar can cause to die of a heart attack", it adds to a growing body of circumstantial evidence. Suggesting that limiting sugar intake can lead to healthier, longer lives. According to Eric Robinson of the University of Liverpool, [8] people who were told that other people were making low-calorie or high-calorie food choices were much more likely to make the same choices themselves. It also revealed that social norms affect how much food people eat. People who are told that others are eating large quantities of food are more likely to eat more. The respondents also sometimes eat balance diet before going to work and just take multi vitamins due to no extra time to prepare. According to Dr. Hilary Seligman [9] an assistant professor of medicine at the University of California, San Francisco, said to eat a healthy diet requires an extraordinary amount of time and cost. It's doable, but it's really, really hard work. The respondents sometimes eat balance diet and also just rely on the vegetables or meat. According to Melissa Joy Dobbins [10] a registered dietitian said that "eating healthy doesn't have to cost more." A person can just eat beans, leafy vegetables, bananas, yogurt, grains, eggs, and tuna and drink plain water and it can meet all the body needs.

The study revealed that the respondents often eat and add extra calories on their meal. According to the Journal of the Academy of Nutrition and Dietetics [8] states that peer pressure play a part in what a person eat and how much a person eat, The evidence reviewed here is consistent with the idea of Eric Robinson [8] that eating behaviors can be transmitted socially," He said the influence is present even if people are not aware of the association -- or if they are eating alone.

Physical activity of the respondents is mostly on household chores and the least do floor exercise such as bending, stretching, yoga and aerobics. This implies that the physical activity of the respondents revolves in doing household works only. According to the study of Edward Archer [11] an exercise scientist and epidemiologist at the University of South Carolina he finds that women watch more TV and get less physical activity today than women did four decades ago. Women have become increasingly physically inactive, sedentary and obese, thereby potentially increased risk of inactivity, adiposity, body fat and chronic noncommunicable diseases. However, the respondents do not usually engage in other physical exercises that will tend to increase cardiac output and lung capacity. This is supported by a study on Lack of exercise [12] that the climatic conditions and the life pattern in Saudi Arabia affect the extent of physical activity carried out daily, particularly by older people. As our population is from an high altitude area it is obvious that the habit of performing physical exercise is very rare. Cardio respiratory fitness is a powerful predictor of all-cause and CVD mortality and appeared to attenuate the relation to BMI. It should be encouraged to increase cardio respiratory fitness by engaging in regular moderate -intensity physical activity to benefit good health. [13] According to Edward Archer [14] physical activity is an absolute prerequisite for health and wellness, it is not surprising that inactivity is now a leading cause of death and disease in developed nations.

In managing stress, the respondents often identify situation that causes stress and often live within their means without getting into debt that they are happy with their work. This is supported with the study of Keller and Nolf (1984) USA[11] that when financial problems arise, it states that many people are experiencing a substantive degree of economic insecurity where there is worry, fear, anxiety and psychology discomfort, stress the laborer is not motivated to work effectively thus affecting the work performance. This implies that the respondents are happy of their salary and benefits from the university. The respondents too have the least on performing regular exercises designed to relieve tension. This implies that the respondents are aware of the possible stressors both in work and at home. However, the respondents may not have enough knowledge on the different exercises to relieve tension that can be done in the office. According to College Park, MD , [15] in his research studies, exercise play an important role in helping people to better endure life's daily anxieties and stressors. Moderate exercise may help people cope with anxiety and stress for an extended period of time postworkout

The respondents rarely do medical checkup and submit self for laboratory test. Based from the study of Dr. Lase Krogsboll [16] of The Nordic Cochrane Centre in Copenhagen, Denmark published in the Cochrane Library from The Cochrane Collaboration shows that some persons do not reduce the risk of dying from serious illness like cancer and heart disease, but may cause unnecessary harm instead. Frequent check up can cause unnecessary physical and emotional strain sometimes especially if a person knows he/she has a serious illness. "One reason for this might be that doctors identify additional problems and take action when they see 
patients for other reasons. Based from Dr. Celeste Robb-Nicholson, [16] a yearly checkup is also an opportunity to reassess a woman's risk for various conditions. Family history, lifestyle, and other factors may change from year to year and affect a woman's risk profile. “A periodic review of what's going on in a woman's life - her family, work, activities, stresses, and joys - helps doctor and patient collaborate on health care decisions.

Most of the respondent's healthy habits involved smoking cigarette at least 1 or more sticks a day; and this means that the respondents are not well informed on the health risk of smoking. Cigarette smoking is a habit that greatly increases chances of developing cardiovascular diseases. Surprising as it may seem, smoking by women in this country is due to cold season during winter and anxiety as being away from their family. Studies have shown several times that the idea that smoking reduces anxiety is a myth. Many people smoke in order to cope with life, but studies have shown that smoking actually increase anxiety- it simply does so after the cigarette's effects have worn off. [17] According to the study of Patricia A. Cavazos-Rehg, PhD, [18] quitting smoking can lower risk of several health problems, anxiety levels and even increase lifespan. The latest study shows that kicking the habit could be good for mental health too.

Likewise, from the result, the respondents do often monitor body weight and they are satisfied with their body weight and work. This is supported by the study of Sabina Vatter [19] of Tallinn University showed that women who were satisfied with their body weight also tended to be more satisfied with their work and relationship, whether or not they were at their "ideal" weight. Such women also had higher self-esteem and lower self-consciousness. Further, respondents sometimes have no adequate amount of sleep of at least eight hours a day that sometimes affects the mood and work performance of the employee. This is supported by the studies of Center for Disease Prevention and Control [20] revealing that on their studies for 2005 to 2006, women were more likely than men to report having trouble sleeping or frequently using sleeping pills or other medications to help them sleep. Sleep deprivation affects decision making, work performance, memory and mood. Sleep deprivation may also be associated with obesity and type diabetes. Indirect societal cost includes increased absenteeism, decreased work productivity and higher injury rates.

Healthy habits revealed quality practices for some of the respondents and others don't have a healthy one. This findings is supported by the theory of William Cockerham [21] a health and lifestyle theory that "not all individual are provided equal opportunity to be healthy". He said individuals have the capacity to interpret their situation, make deliberate choices, and attach subjective meaning to their actions." The unhealthy lifestyle behavior has increased significantly over the past 45 years and may be the greatest public health crisis facing the world. [22] According to Centers for Disease Control and Prevention, 2009, [2] any person who suffers non communicable chronic disease which begins by changing everyday behaviors is related to eating, health habits, stress and physical activity. That means people may need to change their knowledge, attitudes, and beliefs to be productive on their work. This is supported by the research studies conducted by NIOSH (1998) [4] which revealed that unhealthy lifestyle behavior conditions are actually associated with increased absenteeism, tardiness and intention by the workers to quit their job and even death occurs. It damages one's productivity because unhealthy lifestyle behavior on nutrition, physical activity, stress and health habits can slow down the process of the body and mind, makes incompetent, ineffective, and inefficient employee. (Randoff, 1996) [23]

Wellness's programs in the workplace can also help cut health care costs and reduce hospital admissions for employees with chronic illnesses. This implies from the research study conducted by Dr. Soeren Mattke [24] to the employees of Pepsi Company. She found out that disease-management program alone resulted cost reduction of $\$ 136$ per month and a 29 percent drop in hospital admissions among its participants. The PepsiCo program provides a substantial return for the investment made in helping employees manage chronic illnesses such as hypertension, diabetes and heart disease," Likewise the study finds that absenteeism of the employees was dropped.

According to National Institute for Health and Clinical Excellence, 2008 [25] many employers recognize that they have an obligation to the health and wellbeing of their employees. For the employers, healthier workforce is a more productive workforce and yield higher return for society as a whole while ill health leads to social exclusion, lower work output, higher cost in terms of health care and social security.

\section{V1. Conclusions And Recommendations}

Most of the respondents belonged to the age group twenty six to thirty five years old, married, came from the Philippines, academic staff, with two years length of service and received an income ranging from five thousand to ten thousand Saudi riyals.

In terms of nutrition, mostly of the respondents often eat regular meals during the day and not following the balance diet. Physical activity revealed that most of the respondents do the household chores daily, but do minimal physical exercises at home like aerobics, bending and other forms of exercises. The respondents know how to manage stress and enjoy their job. Healthy habits revealed quality practices for some of the respondents. 
We conclude that better emphasis on high quality health education would significantly reduce the burden of non-communicable diseases. Planning a multi strategy approach in physical activity in the university campus is recommended. Integrated health enhancement like seminars on stress management that positively impact employee's health risk and productivity will be conducted. To create a wellness center and utilization of the school clinic in assessing the anthropometric profile of the employees every semester for self awareness or self concern. Construction of a mini-gym. Conduct the same research on male employees.

\section{REFERENCES AND WORLDWIDE WEBSITES}

[1]. World Health Organization. WHO; Geneva: 2003. Annual global movement for health initiative: A concept paper. (WHO Ref. WHO/NMH/PAH/03.1)

[2]. http://www.cdc.gov/nchs/data/hus/hus09.

[3]. http://whatsupksa.net/v3/index.php/health/diabetes-in-saudi-arabia

[4]. http:/www.cdc/noish/stressk.html.

[5]. Atkinson, R. et al. 1996. Introduction to Psychology, $12^{\text {th }}$ Edition

[6]. http:/www.cdc/noish/stressk.html

[7]. http://www.cbsnews.com/news/study-too-much-sugar-is-linked-to-fatal-heart-disease

[8]. Eric Robinson, et al, What Everyone Else is Eating: A Systematic Review and Meta Analysis of the Effect of Informational Eating norms on Eating Behavior. Journal of the Academy of Nutrition and Dietetics, 2014

[9]. http://www.nlm.nih.gov/medlineplus/news/fullstory_143185.html

[10]. Journal of Academy of Nutrition and Dietetics Eat Right, news released Dec. 5, 2013

[11]. http://www.nlm.nih.gov/medlineplus/news/fullstory_143114.html

[12]. Mohsen A.F. El-Hazmi, A.S. Warsy, A.R. Al-Swailem, A.M. Al- Swailem and R. Sulaimani, Diabetes mellitus as a health problem in Saudi Arabia, Saudi Stroke Association

[13]. http://ajcn.nutrition.org/content/69/3/373.full

[14]. http://www.nlm.nih.gov/medlineplus/news/fullstory_143114.html

[15]. http://www.newsdesk.umd.edu/uniini/release.cfm?ArticleID=2777 Aug. 14, 2012 in the journal Medicine and Science in Sports and Exercise

[16]. http://healthland.time.com/2012/10/17/are-health-check-ups-necessary-study-says-not-so-much

[17]. http://www.calmclinic.com/anxiety/lung-quit-smoking

[18]. http://www.natureworldnews.com/articles/6029/20140214/quitting-smoking-good-mental-health-research-finds.htm

[19]. http://mhhehub.ning.com/events/british-psychological-society-annual-conference

[20]. http://www.cdc.gov/nchs/data/hus/hus09

[21]. http://whatshealthyanyways.wordpress.com/2011/10/26/a-healthy-lifestyle-theory

[22]. University of South Carolina, news release, Dec. 2, 2013. Health Day

[23]. http://www.google.com.sa/search?q=national+cancer+institute

[24]. http://www.inc.com/abigail-tracy/take-a-second-look-at-your-wellness-program.html

[25]. http://www.workingforhealth.gov.uk 